\title{
DINÂMICAS DE GÊNERO, EMPREGO E TRABALHO
}

\section{Gender, Work and Job Dynamics}

Iracema Brandão Guimarães (UFBA)

\author{
Informações do artigo \\ Recebido em 23/03/2018 \\ Aceito em 21/04/2018
}

$10.25247 / 2447-861 X .2018 . n 243 \cdot p 58-74$

\begin{abstract}
Resumo
O acesso das mulheres ao mercado de trabalho ao longo das últimas décadas tem sido analisado como resultado de um complexo e lento processo de mudanças socioculturais e econômicas. Neste último aspecto, isso vem ocorrendo através de um longo período de crescimento dos mercados de trabalho em geral, o que perdurou no Brasil até os anos $70 \mathrm{com}$ o aumento do trabalho assalariado, observando-se, nas décadas seguintes, a sua redução, sem que isso afetasse a intensidade do trabalho das mulheres. Essas tendências, de crescimento e de declínio do emprego, em paralelo ao aumento da instabilidade do trabalho, revelam-se como resultados de uma dupla transformação econômica e de suas características locais, ao tempo em que se aprofunda a divisão sexual do trabalho e a precarização e informalidade nas últimas décadas. O presente artigo aborda algumas implicações dessas duas tendências visando a contribuir com as análises do acesso das mulheres ao mercado de trabalho no País.
\end{abstract}

Palavras-Chave: Trabalho. Divisão Sexual. Gênero. Serviços. Informalidade.

\section{Abstract}

Women's access to the labor market over the last decades has been analyzed as a result of a complex and slow process of social-cultural and economic changes. But this has been occurring through a long period of growth in labor markets in general, which persisted in Brazil until the 1970 s with the increase in wage labor, and in the following decades it was reduced without affecting the intensity of the labor market, women's work. These trends of growth and decline in stable employment, along with increased instability, are seen as the result of a double transformation of work and local characteristics, while deepening the sexual division of labor and the precariousness of decades. This article addresses some of the implications of these two trends in order to contribute to the analyzes of women 's access to the labor market in the country.

Keywords: Work. Sexual Division. Gender. Services. Informal Work. 
Os estudos sociológicos e históricos deram origem a duas abordagens sobre as relações de poder exercidas sobre as mulheres: a problemática da divisão sexual do trabalho, entendida como "o suporte empírico que permite a mediação entre relações sociais (abstratas) e práticas sociais (concretas) como hipótese de médio alcance" (HIRATA; KERGOAT, 2003, p. 114) o que remete aos mecanismos de poder, e a discussões sobre a legitimação atribuída às relações de dominação, e às representações e estereótipos que se reproduzem nos espaços de trabalho e acompanham a inserção das mulheres no mercado de trabalho. E a problemática das relações de gênero que busca uma correspondência com as relações de poder supondo que permeiam as diferentes esferas sociais, cujas demarcações são fluidas e não excludentes. Neste caso, compreende-se o gênero como elemento constitutivo das relações sociais baseadas nas diferenças perceptíveis entre sexos; e/ou como forma básica de representação de relações de poder apresentadas socialmente como naturais (Scott, 1993).

Para os objetivos do presente trabalho, adotamos principalmente as contribuições da primeira corrente, tendo em vista a necessidade de compreensão da heterogeneidade do mercado de trabalho brasileiro que tem sido acentuada pelas profundas mudanças ocorridas nas últimas décadas em consequência das dinâmicas gerais e locais da economia e das esferas socioculturais de nossa sociedade. Diante disso, a oferta da força de trabalho tem-se caracterizado por um grande crescimento da População Economicamente Ativa (PEA), que passou de 17,1 milhões de pessoas, em 1950, para 93,5 milhões de pessoas, em 2010 (último censo demográfico), representando um aumento de 5,5 vezes (ALVES, 2013, p. 10). Neste longo período, houve redução contínua da diferença entre homens e mulheres na PEA, quando a participação masculina diminuiu de $80,8 \%$ para $67,1 \%$, ao passo que a participação feminina mais que triplicou, saltando de $13,6 \%$ para 49,9\% (ALVES, 2013). Cabe esclarecer que as mudanças metodológicas introduzidas nos instrumentos de coleta do Censo Demográfico (IBGE) e das Pnads (IBGE) podem refletir-se nos dados, a exemplo da inclusão da produção familiar agrícola e de atividades para autoconsumo, mas a tendência ao aumento da participação feminina no longo prazo se confirma. Em outra fonte, a Pesquisa Mensal de Emprego (PME, IBGE) indica: - a participação das mulheres na População 
Economicamente Ativa (PEA), correspondia a 45,5\% em 2008, com as ocupadas representando $44,4 \%$ isto é, 9,4 milhões.

Essa tendência já vinha sendo destacada anteriormente, quando Bruschini (2000, p. 14) demonstrou a "intensidade e constância do crescimento do trabalho feminino desde 8590, quando as mulheres desempenharam papel mais relevante no crescimento da PEA taxas de $48 \%$ na semana do Censo e de $53 \%$ no ano de referência". As explicações para essa significativa mudança são atribuídas, tanto a necessidades econômicas e oportunidades oferecidas pelo mercado de trabalho, como às transformações que afetaram as mulheres e as famílias brasileiras implicando sua liberação para o trabalho, com destaque para a tendência declinante do tamanho da família, diminuição progressiva do número médio de filhos, e aumento dos domicílios chefiados por mulheres: 14\% em 1980, 20\% em 1990. Acrescente-se que em 2010, as mulheres chefiavam 38\% dos lares brasileiros (IBGE, 2010).

A contínua participação feminina que passou de $40 \%$ da Força de Trabalho brasileira (2000) para $49 \%$ (2010) tem sendo muito enfatizada e manteve-se mesmo nos períodos de reaquecimento da indústria quando houve aumento modesto do emprego e essa participação se revelou maior no setor de serviços, como se verá adiante.

\section{O trabalho na indústria}

No longo prazo, as mudanças ocorridas na indústria e na sua absorção diferenciada da força de trabalho podem ser observadas desde o inicio da industrialização brasileira, quando as mulheres foram incorporadas em ramos que utilizavam baixa tecnologia como o Setor Têxtil no qual, até 1930, 72\% da força de trabalho eram mulheres e crianças, geralmente migrantes (RAGO, 1997, p. 581). O processo de estruturação do mercado de trabalho que ocorrera entre 1930 e 1970 em consequência da dinâmica da industrialização levou à organização do estatuto do trabalho e introdução posterior dos métodos fordistas resultando em aumento do número de ocupações formais mas causando um declínio da força de

\footnotetext{
1 A Pesquisa Mensal de Emprego - PME - implantada desde 1980, produz indicadores para o acompanhamento conjuntural do mercado de trabalho nas regiões metropolitanas brasileiras. Trata-se de uma pesquisa domiciliar urbana realizada através de uma amostra probabilística, planejada de forma a garantir os resultados para os níveis geográficos em que é produzida. As diferenças se devem aos períodos da coleta dos dados, nesse caso, mensais.
} 
trabalho feminina no setor: em 1950 elas representavam apenas 23\% dos empregados na indústria (RAGO, 1997, p. 584). Destacando o caso de São Paulo, Blay (1978, p. 140) também mostrou que as mulheres eram absorvidas principalmente nas indústrias tradicionais, como no ramo têxtil ( $52 \%$ ) e de vestuário (57\%), geralmente em atividades não qualificadas como operárias nas linhas de produção. Já o trabalho qualificado, mais presente nas empresas consideradas modernas, as absorvia em atividades administrativas, como secretárias, técnicas em serviços de saúde e assistência social, enquanto os ramos mecânico, metalúrgico e papel e celulose mantinham-se restritivos ao trabalho feminino.

O papel exercido pelas mudanças tecnológicas (início dos anos 80) e a introdução de novos modelos organizacionais (meados dos anos 9o), explicariam as mudanças que se seguiram. Inicialmente, adotada na indústria, e posteriormente nos serviços, a especialização flexível $^{2}$ tinha como objetivo o controle da queda da produtividade e do lucro, considerados responsáveis pela retração econômica e redução na geração de empregos, levando a uma reorganização no mercado de trabalho que Hirata $(1998$, p. 8) identifica através de uma dupla transformação:

a) inicialmente, tratava-se de um processo concentrado nas grandes empresas, localizadas nos países capitalistas centrais, exigindo estabilidade e implicação do sujeito no processo de trabalho, para a realização de atividades que requeriam características distintas dos modelos produtivos anteriores do taylorismofordismo, como autonomia, iniciativa, responsabilidade, comunicação, e intercompreensão, além de conhecimentos das novas tecnologias;

b) em paralelo a essa concentração, nos outros setores, e para o restante dos trabalhadores, ocorreu um processo diferenciado, gerando instabilização e precarização dos laços empregatícios, acompanhados de aumento do desemprego, disseminação do emprego considerado precário, e tendência à

\footnotetext{
2 Esse conceito é atribuído a Piore e Sabel (apud ABREU, 1994, p 52) que procuram dar um caráter diferenciado à especialização flexível em relação à produção em massa que caracterizava o fordismo. Ressaltam, principalmente, o fato de que na produção em massa existe uma forte divisão do trabalho, onde o trabalhador se limita à sua tarefa enquanto que, na especialização flexível, não haveria uma divisão tão rígida do trabalho: o trabalhador se torna multifuncional, adquirindo uma qualificação que lhe permitiria desenvolver múltiplas funções dentro de um grupo de trabalho.
} 
flexibilidade no uso da mão de obra. Segundo Hirata, neste último caso, tratou-se de um movimento macrossocial e mundializado (HIRATA, 1998, p. 8).

Essa dupla transformação é igualmente observada por Antunes (2009, p. 235) ao mostrar que a reestruturação produtiva implicou em redução do proletariado industrial, fabril, tradicional, manual, estável e especializado, herdeiro da era da indústria verticalizada que ocorreu especialmente nos países capitalistas avançados; outra tendência se caracteriza pelo "aumento de um novo proletariado fabril e de serviços em escala mundial, presente nas diversas modalidades de trabalho precarizado. São os terceirizados, subcontratados, parttime, entre outras formas [...] ", cujo aumento se deve a uma conjuntura de crescimento mínimo da produção, o que torna o desempenho do mercado de trabalho restritivo na geração de empregos formais (com registro, carteira assinada e benefícios assegurados) e não cria o nível necessário de ocupações para incluir a maior parte da população.

Os efeitos dessas transformações do mercado de trabalho são desiguais para homens e mulheres enquanto trabalhadores, tendo-se em vista a relação com a qualificação. A introdução de novas tecnologias baseadas na microeletrônica supostamente permitiria a informatização nos processos de trabalho, resultando em eliminação da força física, trabalhos pesados, sujos, e permitindo uma maior igualdade entre trabalhadores por sexo, ou seja, conduzindo a maior igualdade de gênero. Segundo Abreu (1994, p. 54), ao contrário do que se esperava, houve uma reconstrução contínua das diferenças que mantinham a distância entre o trabalho qualificado dos homens e o trabalho desqualificado das mulheres, o que não se explicaria pelas determinações técnicas associadas à noção de qualificação em sua relação com a divisão sexual do trabalho. Isto pode então ser apreendido em diferentes dimensões (HIRATA, ROGERAT, KERGOAT apud ABREU, 1994): a qualificação do emprego - definida pelas exigências do posto de trabalho; a qualificação do trabalhador - sendo mais ampla que a primeira, incorpora as qualificações sociais ou tácitas (que tradicionalmente explicaram a inserção diferenciada de homens e mulheres nos ramos e setores industriais; e a qualificação enquanto relação social - entendida como resultado de uma correlação de forças entre capital e trabalho. Através desses conceitos, a relação vista como negativa das mulheres com a tecnologia tende a ser repensada como dimensão de poder (ou seja, relação de gênero), considerando-se que existiria uma apropriação da esfera tecnológica pelos 
homens, o que leva a uma construção social "do feminino" como incompetente tecnicamente (ABREU, 1994, p. 56).

Os novos conceitos associados ao perfil de trabalhador flexível têm conduzido a uma valorização da importância da formação profissional condizente com os padrões de competitividade de mercado, bem como, a uma atenção às tendências de mercados e empresas "enxutas" em sintonia com a gestão de qualidade, envolvimento dos trabalhadores, empregabilidade, trabalhador polivalente e multifuncional. Segundo a Pesquisa Mensal de Emprego/IBGE, entre o total das mulheres ocupadas em 2008, 13,1\% estavam na Industria. Já o Ministério do Trabalho e Emprego apresenta uma comparação em longo prazo, indicando que em 1995 as mulheres ocupavam 22,5\% dos postos formais do setor da indústria, e em 2015, esse percentual aumentou para 25,8\%. Os segmentos com maior crescimento de mulheres empregadas são: - mineração $(65,8 \%)$, material de transporte $(60,8 \%)$, alimentos e bebidas $(49,3 \%)$, madeira e mobiliário $(39,3 \%)$, a indústria mecânica (37,3\%) e papel e gráfico $(24,7 \%)$.

De modo geral, a participação feminina nas empresas industriais cresceu $14,3 \%$ nesses 20 anos. Em ramos considerados predominantemente masculinos, a proporção de postos de trabalho ocupados por mulheres apresentou alta de $39,9 \%$ na metalurgia, de 37,3\% na indústria mecânica e de $31,1 \%$ na construção civil. Neste último caso, Soares $(2015$, p. 8) aponta que a atividade feminina na construção civil elevou-se de $7,14 \%$ para $8,94 \%$ no conjunto dos seus trabalhadores, o que representa em números absolutos um aumento de 119.538, em 2007, para 276.588 mulheres em 2013. Através de pesquisa qualitativa (Silva, apud Soares, 2015) se observa que a inserção das mulheres na construção civil ocorre inicialmente nas atividades de limpeza, durante e ao final da obra, quando as empresas iniciam contratações para as ocupações de assentamento de cerâmicas e acabamentos, confirmando-se que este acesso feminino deve-se às necessidades do capital de redução de custos com contratação da mão de obra.

Nas atividades que envolvem operações de máquinas e equipamentos reconhece-se que em muitos casos, tratava-se de atividades antes qualificadas e que passaram a ser repetitivas, com pouca responsabilidade, justificando reorientações das políticas de contratação com rebaixamento de salários e redução de custos, o que permite a incorporação das mulheres (HIRATA, KERGOAT, 2003, p 32; ARAÚJO, 2007, p. 80). Portanto, os aspectos contraditórios se mantêm, ainda que as mudanças no plano geral indiquem que diversas 
ocupações e profissões qualificadas se abriram às mulheres, como engenheiras, analistas de sistemas, programadoras, técnicas especializadas e outras. Mas de um modo geral, pode-se concordar com Lombardi (2005) quando observa que os estereótipos e concepções de gênero que dificultavam o ingresso das mulheres em certas especialidades e áreas de trabalho perderam parte de seu poder de intimidação, mas, internamente, a divisão sexual do trabalho se reproduziu.

\section{O trabalho nos serviços}

O setor dos serviços visto anteriormente como suporte e apoio da produção industrial (OLIVEIRA, 1997, p. 25) também passou por mudanças tecnológicas e adoção de novos modelos organizacionais em alguns dos seus ramos o que alterou o seu papel na geração das ocupações. Sassen $(1998$, p. 27$)$ indica que isso ocorreu também na década de 80 quando as finanças e serviços especializados tornaram-se os principais componentes das transações internacionais no contexto da globalização, e Chesnais (1996, p.17) define um estilo da acumulação que adquiriu novas formas a partir da centralização do capital financeiro através dos fundos de pensão, fundos mútuos, e títulos como seus veículos. Portanto, supõe-se que o nível de desenvolvimento econômico determinou impactos diferenciados dos serviços sobre a produção, ampliando-se o deslocamento da força de trabalho e concentrando as atividades de serviços que passam a absorver mais de metade da População Economicamente Ativa nos anos 90 ( $54 \%$ para $58 \%$ ).

A dupla transformação do trabalho através da concentração das transformações nas grandes empresas e da instabilização e precarização dos laços empregatícios nas demais, está presente no amplo setor dos serviços como pode ser observada a seguir.

Quadro 1 - Participação Feminina nas Atividades de Serviços e Comércio.

\begin{tabular}{|l|l|}
\hline Administração Pública, Educação, Defesa, Segurança, Saúde & $22,0 \%$ \\
\hline Outros Serviços e Outras Atividades & $17,0 \%$ \\
\hline Serviços Domésticos & $16,5 \%$ \\
\hline Serviços prestados à Empresa & $13,3 \%$ \\
\hline Comercio & $17,4 \%$ \\
\hline
\end{tabular}

Fonte: IBGE - Pesquisa Mensal de Emprego (PME), 2015. 
O Quadro 1 apresenta uma classificação dos segmentos nos quais se concentra a força de trabalho feminina, com sua conhecida heterogeneidade. Os serviços coletivos e a administração pública continuam a concentrar o trabalho das mulheres $(22,0 \%)$ ainda que 0 seu movimento de geração de ocupações venha oscilando e declinando. Segue-se o agrupamento de outros serviços que incluem aqueles prestados às famílias, como alimentação e higiene pessoal (17\%), além dos serviços domésticos $(16,5 \%)$. O segmento dos serviços prestados à empresa que correspondem aos especializados, mencionados por Sassen (1998) empregam-se 13,3\% das mulheres, e o comercio, 17, $4 \%$.

Nas atividades de serviços estão incluídas inúmeras atividades informais e precárias cuja ampliação se deve também ao restrito crescimento das ocupações formais, assalariadas, com registro, em dois aspectos: primeiro, porque a expansão do emprego em serviços pósanos oitenta, como visto acima, é consequência da restrição do emprego industrial e também do surgimento de novas formas de atividades articuladas ao emprego das tecnologias e à flexibilização do trabalho; segundo, porque essas passam a conviver com as formas de prestação de serviços e comércio pré-existentes, realizadas por trabalhadores autônomos ou empregados sem vínculo empregatício, geralmente de baixa renda. Neste caso, mas também nos novos serviços especializados, existem graus de informalidade, tratando-se de um conceito que mereceu ampla reformulação, conforme Cacciamali (2000), que propõe a consideração de dois 3fenômenos da informalidade associados ao mercado de trabalho: a reorganização do trabalho assalariado, correspondente à reorganização no mercado de trabalho citado acima como dupla transformação; e o autoemprego e outras estratégias de sobrevivência - incluindo-se, nesse último caso, a maior parte das atividades antigas e anteriores aos processos recentes.

Todo esse quadro serve para realçar os desafios que se colocam para uma reconstrução da heterogeneidade que caracteriza o conjunto das mulheres trabalhadoras, indicando a necessidade de se reunir informações sobre as diferenças de gênero nele existentes, tanto na velha informalidade, como na nova informalidade, esta última resultante da precarização do conjunto do mercado. Tais informações explicam a atual tendência de

3 Houve uma ampla crítica ao conceito de setor informal (OIT, 1972), que partia de critérios como a organização da produção baseada em pouco capital, a não separação nítida entre capital-trabalho, o uso de pequeno número de trabalhadores remunerados, e principalmente, a participação da força de trabalho familiar. 
crescimento da atividade feminina que se viabiliza mais através da informalidade, já que a proporção de mulheres que trabalham sem carteira assinada aumentou de 39, 8 para 40, $9 \%$ , enquanto entre os homens esta proporção diminuiu, o que deve resultar, tanto da saída das mulheres do emprego regular nos setores público e também privado, como do ingresso recente daquelas que só encontram oportunidades na informalidade.

Esse movimento da força de trabalho se amplia no segmento das empregadas sem carteira assinada (exclusive o emprego doméstico no período referido), e também no próprio emprego doméstico - atividade predominante entre os "serviços pessoais" (GUIMARÃES, 2007, p. 113). Mas a verdadeira dimensão da informalidade só pode ser avaliada ao somaremse os trabalhadores por conta própria aos empregados sem contrato:

Quadro 2 - Ocupados (sem carteira assinada) e autônomos.

\begin{tabular}{|l|l|}
\hline & \multicolumn{1}{|c|}{ Número absoluto } \\
\hline 2016 & 32,6 milhões \\
\hline 2017 & 34,31 milhões \\
\hline
\end{tabular}

Fonte: IBGE, 2018.

Os dados recentes confirmam um aumento desse segmento no total do pessoal ocupado no país que não contam com "emprego protegido". Como alguns estudos vêm mostrando, o intenso crescimento do trabalho feminino é convergente com o aumento do trabalho precarizado, o que redefine as desigualdades e assimetrias de gênero. Tudo isso ocorre, conforme reafirma Proni (2016, p. 70), em um

contexto de baixas taxas de crescimento econômico e insuficiência de geração de empregos para absorver trabalhadores jovens ou reabsorver adultos desempregados, e principalmente, de inserir o conjunto da população trabalhadora no setor organizado em moldes capitalistas ou no setor público.

Em prosseguimento à agenda neoliberal que adota políticas destinadas a incentivar o empreendedorismo e as microempresas, essas políticas revelam uma mudança de abordagem, na qual se procura tirar da ilegalidade as atividades antes classificadas como informais. Segundo Proni (2016, p. 71), isso implica em sobreposição de novas formas de manifestação do fenômeno em relação à concepção tradicional destas atividades: relações de emprego consideradas disfarçadas na figura de pessoa jurídica, e o trabalho autônomo 
modificado, bem como, outras formas, a exemplo de falsas cooperativas, terceiro setor, trabalho voluntário.

Tendo em vista a mudança de abordagem em relação às atividades anteriormente vistas como informais, cabe apresentar em seguida as linhas de consideração desfavoráveis e favoráveis à sua implementação.

\section{Argumentos desfavoráveis}

Concordamos com o argumento de que no plano macrossocial, a promoção do setor informal na perspectiva da geração de emprego e renda tende a justificar a retirada do Estado da esfera social, e a economia informal passa a ganhar proeminência sobre a economia formal na atribuição da geração de empregos. Essa questão é considerada por alguns autores, mostrando que isso equivale a uma estratégia que transfigura o que antes era tido como alternativo, em algo bom e preconizado como saudável e recomendável (GHON, 2006, p. 296).

Na conjuntura de trabalho precário e informal, os trabalhadores são levados a lutar pela manutenção de um emprego e não mais pelas condições de trabalho internas a uma categoria, contribuindo para a perda de espaço dos sindicatos de trabalhadores que é agravada pela grande dificuldade de organização que caracteriza a economia informal.

O desenvolvimento de políticas de apoio às atividades informais estimula a abertura de negócios, a contratação de mão de obra com redução de custos, mas sem direitos sociais e sem filiação sindical.

A título de exemplo, a estimativa oficial é de que existem 7,8 milhões de MEls, Microempresários Individuais cadastrados no país, mas não há dados sobre quantos deles estão ativos (IBGE, PNAD CONTíNUA, 2018).

\section{Argumentos favoráveis}

Tem sido crescente a avaliação favorável à implementação dessas atividades embora modificadas. Aponta-se, principalmente, a importância da criação de canais de expressão para os diferentes grupos sociais, a ideia de democratização do Estado, e de busca de participação da sociedade civil, concretizadas através da formação de comissões e câmaras. 
Para alguns autores, isto favorece os objetivos feministas de ampliação do acesso às arenas decisórias, o que pode tornar-se um dos centros das demandas como no caso do trabalho formal e das cotas e ações afirmativas.

Através de pesquisa realizada para avaliação dos Conselhos Gestores de programas sociais desenvolvidos pelo poder público para parcelas da sociedade civil observaram-se algumas características importantes: - os conselhos compartilhados para a gestão pública permitem a formação de redes predominantemente femininas, com membros entre 30-50 anos de idade, geralmente de escolaridade superior, o que indica um perfil de "incluídos da população" (GHON, 2006, p. 169).

Portanto, a observação acima indica que existe um amplo potencial para a participação de representantes com perspectiva feminista nestes espaços decisórios mas deve-se assegurar a presença de categorias de trabalhadoras nesses espaços para a negociação dos temas relativos ao trabalho.

De igual importância, são as instituições mediadoras das relações entre Estado/governo, trabalhadores e empregadores, como o caso da OIT, através de suas entidades representativas e da formação de "redes de conversas tripartites" na América Latina e Cone Sul.

Lima e Costa (2007) observam que nesses espaços se tem buscado estabelecer um diálogo social para a igualdade de oportunidades no emprego para mulheres e homens, contemplando-se, ainda, a perspectiva de se estabelecer parâmetros para o reconhecimento legal do setor informal como uma categoria de trabalhadores/as que devem ter direitos, e a possibilidade de proteção da lei - onsiderando-se a contribuição desse setor para a economia.

Em todos esses casos, a postura propositiva aproxima-se daquela de "formalizar o informal" que prevaleceu no período de concepção destas políticas, cujo objetivo era o incremento da renda entre trabalhadores do setor envolvendo instituições como o IPEA e a OIT.

Outras observações dizem respeito à descontinuidades dessas políticas:

a) Programas como o Patras - Programa de Apoio ao Trabalhador Autônomo de Baixa Renda - com inserção regional, previa a instalação de postos de atendimento a diversas categorias de autônomos e hoje se concentra apenas no cadastramento de diaristas domésticas. 
b) Do ponto de vista dos trabalhadores e dos segmentos beneficiados pelas políticas, as avaliações favoráveis à filosofia de intervenção são crescentes, entre as quais prevalece o Comunidade Solidária que se propõe a dar aos trabalhadores os conhecimentos e instrumentos para a iniciativa própria, em substituição à filantropia e assistencialismo.

C) Nesta mesma perspectiva situam-se algumas experiências como o Programa Banco do Povo que voltava-se para a capacitação de mulheres como empreendedoras, realizando cursos baseados em metodologias que visam a educação para o crédito

\section{O Terceiro Setor e as Ongs}

Como estamos destacando, as políticas de apoio ao setor informal foram fortemente endossadas pela ação estatal no Brasil e também estimuladas nas instituições do Terceiro Setor, o que representa uma segunda vertente de apoio às atividades informais, especialmente as ONGs que sempre tiveram um papel atuante na geração de renda e na oferta de microcrédito no Brasil. Suas primeiras iniciativas localizam-se nas décadas de 70/80, com o propósito de se ofertar às populações mais pobres oportunidades de financiamento às suas atividades produtivas. Essas organizações se caracterizaram por um desenvolvimento irregular, tanto do ponto de vista jurídico, como institucional, no exercício das atividades de intermediação financeira.

Esta intermediação foi gerada pelos grandes bancos internacionais e empresas multinacionais que passaram a patrocinar projetos associativistas a clientes carentes, através das Câmaras de Relações Comerciais situadas em outros países, criando programas e espaços de debates sobre o Terceiro Setor. No final dos anos 90, a Lei nº 9.790 (Lei do Terceiro Setor) estabeleceu o marco jurídico para a criação das OSCIPs/ Organizações da Sociedade Civil de Interesse Público, que permitiu a prática de financiamentos em condições de mercado. Entre 1994 e 1999, a Comissão Europeia, órgão executivo da Comunidade Europeia, destinou 73 milhões de euros a projetos de parceria entre ONGs europeias e brasileiras atuantes em diversos setores. Em 2002, a cidade de São Paulo foi escolhida pela Comissão (com apoio de 81 cidades europeias e latino-americanas) para coordenar a Rede 10 do Programa Urb-Al, com o objetivo de luta contra a pobreza urbana (GHON, 2006, p. 162). 
Entre as características desses programas, destacam-se: o repasse de recursos e coordenação de redes de discussão, intercâmbio de informações, criação de instrumentos de mediação, troca de experiências e proposições para a solução de problemas. Um dos exemplos é o programa "Emprego e Cidadania Ativa das Mulheres", desenvolvido em São Paulo, integrado à rede da Urb-Al.

Essas organizações atuam em regiões e um dos exemplos relevantes foi a União Nordestina de Assistência a pequenas organizações, conhecida como programa UNO, especializado em microcrédito e capacitação para trabalhadores de baixa renda do setor informal. Criada no final dos anos 70, nos municípios de Recife e Salvador, esta organização contava com assistência técnica da organização não governamental Accion International - na época AITEC - e com a participação de entidades empresariais e bancos locais, desenvolvendo operações baseadas na metodologia do "aval moral", ou seja, fiadores entre os participantes anteriores.

Entre outras experiências de utilização do "aval solidário" no setor de microcrédito podem ser citadas: - CEAPE/RS - Centro de Apoio aos Pequenos Empreendimentos Ana Terra, instituído sob a forma de uma organização não governamental, criado em 1987 em Porto alegre; - POTOSOL; Banco da Mulher, seção Bahia, com apoio do fundo das Nações Unidas para a infância (UNICEF) e do Banco Internacional de Desenvolvimento (BID), cujo programa de microcrédito iniciado em 1989 também utilizava a metodologia de grupos solidários; - SEBRAE/PA, o serviço à micro e pequena empresa cuja atuação com microcrédito tem o objetivo de ampliar as oportunidades de acesso ao crédito para os pequenos empreendimentos, principalmente, os informais.

\section{Conclusões}

O conjunto da análise apresentada visa a oferecer uma contribuição para se pensar as relações sociais de sexo, com base nos conceitos de divisão sexual do trabalho e relações de gênero, vistas como hierarquizadas, assimétricas, ou mesmo antagônicas, como resultado da opressão que ocorre entre categorias de sexo socialmente construídas. Para isso, é fundamental o critério indicado por Hirata; Kergoat, (2003, p. 114) quando propõem uma separação didática entre as noções de relações sociais sexuadas (remete à totalidade das práticas) e divisão sexual do trabalho, um aspecto das relações sociais sexuadas. 
Assim, a revisão empreendida ao longo deste trabalho buscou articular a produção de conhecimentos sobre o trabalho feminino e sua contribuição para a intervenção e formulação de políticas de equidade. Como buscamos demonstrar, os setores da indústria e dos serviços contam com participação diferenciada das mulheres e no primeiro - cenário privilegiado da sociologia do trabalho - a capacidade de incorporação da força de trabalho vem sendo reduzida em função das mudanças que ocorreram no processo e na organização do trabalho e que afetaram e afetam as relações dos trabalhadores inseridos em contextos de mudanças tecnológicas, segundo relações de sexo-gênero. O segundo - bem menos focalizado, representa o setor que mais emprega mulheres da classe trabalhadora e também apresenta maiores desafios para a perspectiva da transversalização e da promoção da equidade de oportunidades entre os sexos.

As novas tendências no mercado de trabalho indicam que a heterogeneidade se aprofunda. O fato de que os primeiros Programas de Apoio foram criados em um contexto de concepção do informal como fenômeno passageiro, contrasta com a concepção atual que emergiu no contexto neoliberal dos anos 9o, cuja postura conduz à permanência do "setor informal" - não mais como " tábua de salvação" diante da restrição de empregos mas como segmento que passa a ser incentivado, e mesmo subsidiado As possíveis ambiguidades desta postura são evidentes, diante do crescimento de uma nova informalidade no contexto da precarização do mercado de trabalho, o que lança maiores desafios e dificuldades com o surgimento de ocupações "flexibilizadas" que envolvem, tanto atividades rentáveis de profissionais liberais e prestadores de serviços qualificados, como vendedores ambulantes e prestadores/as de serviços.

Esta nova informalidade se sobrepõe à velha informalidade com sua heterogeneidade e complexidade, abrigando o trabalhador de rua, e o grande segmento da prestação de serviços que comporta, desde as empregadas domésticas sem carteira assinada, às diaristas de diferentes tipos, às prestadoras de serviços em higiene e beleza, como cabeleireiras e manicuras, até as garçonetes e demais atividades em estabelecimentos de alimentação, hotelaria, lazer. Trata-se, portanto, de desigualdades entre as classes sociais, atentando-se para as sensíveis diferenças que expressam a ausência de garantias trabalhistas entre os novos e velhos informais.

Esta questão aumenta as dificuldades para a intervenção e para o desenho de políticas que agreguem as questões de gênero e poucas serão as mudanças percebidas no plano 
qualitativo em relação ao trabalho informal, diante das condições de trabalho marcadas pela ausência de estabilidade, de vínculo empregatício, e de garantias trabalhistas. No plano das políticas públicas a postura de ampliação da participação nos espaços decisórios torna-se viável, pela redefinição (neoliberal) das próprias estruturas institucionais que preveem a participação da sociedade civil.

Segundo o documento do Centro Feminista de Estudos e Assessoria/ CFEMEA (2006) a amplitude do amplo mercado de trabalho no qual se ampliam as atividades informais sugere que o impacto de uma reforma trabalhista orientada pelo critério de igualdade de gênero poderia ter efeitos limitados. Diante disso, torna-se importante combinar mudanças dos marcos regulatórios do trabalho com políticas públicas de caráter universal que possam incidir sobre as oportunidades de inserção das mulheres, acompanhadas das propostas de expansão das creches e pré-escolas que aumentam as possibilidades das mulheres nas camadas populares poderem desenvolver atividades de pequenos negócios.

Mas permanecem os desafios e o principal deles é que um número pequeno de mulheres tem acesso às instituições de microcrédito e as poucas avaliações existentes sobre essas experiências apontam as dificuldades dos trabalhadores/as renovarem os créditos financeiros e encontrarem as formas adequadas de distribuição de mercadorias e de contratação de seus serviços, o que aponta em termos gerais para as dificuldades de acesso a informações. Os dados são dispersos, e a existência de organizações direcionadas para as mulheres constituem casos importantes que podem inspirar muitos outros, buscando-se minimizar o problema da reduzida experiência feminina na gestão de pequenos negócios e multiplicar a possibilidade de retirada de muitas mulheres do trabalho doméstico atribuindoIhes maior autonomia de vida.

\section{Referências}

ABREU, Alice de Paiva. Especialização Flexível e Gêneros. São Paulo em Perspectiva. São Paulo, v. 8, n. 1, p. 52-57, jan./mar. 1994.

ALVES, José Eustáquio Diniz. O crescimento da PEA e a redução do hiato de gênero nas taxas de atividade no mercado de trabalho. Rio de Janeiro: UFRJ, 2013. Disponivel em: http://www.ie.ufrj.br/aparte/pdfs/. Acesso em: 30 abr. 2018.

ANTUNES, Ricardo. Século XXI: nova era da precarização estrutural do trabalho? In: ANTUNES, Ricardo; BRAGA, Rui. Infoproletários, degradação real do trabalho virtual. São Paulo: Boitempo, 2009. p. 231-238 
ARAÚJO, Ângela. Ameaças aos direitos trabalhistas das mulheres e a configuração de novas demandas relativas às questões de gênero. In: BEZERRA, M. Ednalva; COSTA, Ana (Org.). Transformando as relações de trabalho e cidadania. Snmt/CUT; Salvador: Neim/UFBA; FastDesign; SSA; 2007.

BLAY, Eva. Trabalho Domesticado: A mulher na indústria paulista. São Paulo: Ed. Hucitec, 1978.

BRUSCHINI, Cristina. Gênero e trabalho no Brasil: novas conquistas ou persistência da discriminação? In: ROCHA, M. Isabel Baltar (Org.). Trabalho e Gênero, Mudanças, Permanências e Desafios. São Paulo: Abep. Nepo/Unicamp; Ed. 34, 2000.

CACCIAMALI, M. C. Globalização e processo de informalidade. In: Economia e Sociedade. Campinas: UNICAMP. Instituto de Economia, n. 14, jun. 2000. Disponível em: http://www.eco.unicamp.br/publicacoes/revista.html. Acesso em: 9 out. 2003.

CHESNAIS, François. A Mundialização do Capital, Xamâ. São Paulo: VM Editora, 1996.

COSTA, Ana Alice, LIMA, Maria Ednalva. Introdução. Transformando as relações de trabalho e cidadania. Snmt/CUT, Neim/UFBA, FastDesign Ed, 2007.

GHON, Maria da Gloria. Associativismo em São Paulo: Novas formas e participação no planejamento urbano da cidade. In: NUNES, Brasilmar (Org.) Sociologia das capitais brasileiras: participação e planejamento urbano. Brasília: Líber Ed., 2006.

GUIMARÃES, Iracema Brandão. Informalidade e Gênero: tendências recentes, in Transformando as Relações de Trabalho e Cidadania. Salvador: CUT / NEIM, SA, 2007.

HIRATA, Helena. Reestruturação produtiva, trabalho e relações de gênero. In: Revista Latinoamericana de estudos del trabajo. São Paulo, ano 4, n. 7, 1998.

HIRATA, Helena; Kergoat, Daniele. A divisão sexual do trabalho revisitada: As Novas Fronteiras da Desigualdade, Homens e Mulheres no Mercado de Trabalho. São Paulo: Editora SENAC, 2003.

INSTITUTO BRASILEIRO DE GEOGRAFIA E ESTATÍSTICA (IBGE). Pesquisa Mensal de Emprego (PME). [S. I., S. d.]. Disponível em:

https://ww2.ibge.gov.br/home/estatistica/indicadores/trabalhoerendimento/pme mulher/Supleme nto Mulher_2008.pdf. Acesso em: 11 abr. 2018.

INSTITUTO BRASILEIRO DE GEOGRAFIA E ESTATÍSTICA (IBGE). PNAD 2005, 2006: Síntese de Indicadores. Rio de Janeiro, 2005, 2006.

LOMBARDI, Rosa, A engenharia como profissão. In: ENCONTRO DA ASSOCIAÇÃO NACIONAL DE PÓS-GRADUAÇÃO E PESOUISA EM CIÊNCIAS SOCIAIS (ANPOCS), 20., Caxambu, 2005. Anais... Caxambu, 2005.

OLIVEIRA, Francisco. O Terciário e a Divisão Social do Trabalho. Estudos Cebrap, n. 24, 1997.

PORTAL DA INDÚSTRIA. Agência de Notícias CNI. Participação de mulheres no mercado de trabalho industrial cresce 14,3\% em 20 anos. Postado em: 8 de nov. 2016, às 17:46. Disponivel em: http://www.portaldaindustria.com.br/agenciacni/noticias/2016/11/participacao-de-mulheres-nomercado-de-trabalho-industrial-cresce-143-em-20-anos/Acesso em: 30 abr. 2018. 
PRONI, Marcelo W; OLIVEIRA, T. Um mercado de trabalho heterogêneo e flexível: um problema persistente no Brasil. Revista da Associação Brasileira de Estudos do Trabalho (ABET). [S. I.], v. 15, n. 2, 2016.

RAGO, Margareth. As operárias, a emancipação e a sexualidade femininas no início da industrialização brasileira. In: DEL PRIORE, Mary; BASSANEZI, Carla (Org.). História das Mulheres no Brasil. São Paulo: Contexto/Ed. UNESP, 1997.

SASSEN, Saskia. As cidades na economia mundial. São Paulo: Studio Nobel, 1998.

SCOTT, Joan. Gênero: uma categoria útil de análise histórica. Revista Educação \& Realidade. [S.I.], v. 20, n. 2, 1995

SOARES, Erika L. Almeida. Reestruturação produtiva e divisão sexual do trabalho: notas para um estudo sobre o setor da construção civil. In: CONGRESSO BRASILEIRO DE SOCIOLOGIA, 17., Porto Alegre, 2015. Anais... Porto Alegre, SBS, 2015.

Iracema Brandão Guimarães

Professora da Universidade Federal da Bahia no Dep. de Sociologia, e Programa de Pós-Graduação em Ciências Sociais. Pesquisadora do CNPO e Centro de Estudos e Pesquisas em Humanidades. Email: iracema.brandao6o@gmail.com 